\title{
Who Needs Parent-teacher Meetings in the Technological Era?
}

\author{
Davidivitch Nitza ${ }^{1} \&$ Yavich Roman ${ }^{1}$ \\ ${ }^{1}$ Ariel University, Ariel, Israel \\ Correspondence: Yavich Roman, Ariel University, Ariel, Israel \\ Received: November 7, 2016 \\ Accepted: December 12, 2016 \\ Online Published: December 13, 2016 \\ doi:10.5430/ijhe.v6n1p153 \\ URL: http://dx.doi.org/10.5430/ijhe.v6n1p153
}

\begin{abstract}
In this study we shall examine parent-teacher meetings in the technological era, i.e., whether parent-teacher meetings are still relevant, how they should be conducted, whether it is necessary to change the structure of the parent-teacher meeting or its conception by parents, students, and teachers. For this purpose, identical questionnaires were administered to teachers and parents, with an added question on suggestions for increasing efficacy. The questionnaires show that there is need for change. This study is a pioneer study, and therefore it proposes suggestions for further research. Furthermore, a proposal for increasing the efficacy of parent-teacher meetings was offered by the researchers. Once further research is undertaken in this field, it will be possible to perform a more thorough exploration of the issue, of which the current study provides an initial overview.
\end{abstract}

Keywords: Parent-Teacher Meetings, Computer-assisted communication, Parent Involvement

\section{Introduction}

The first school in Jewish history was established two thousand years ago. Shimon Ben Shetach, who headed the Sanhedrin during the Hasmonean Kingdom (1st century AD), decreed "that all children should go to school" (Jerusalem Talmud). He understood that, in light of the cultural war against the Greeks, it was necessary to define the nation's institutions (and hence also added a regulation concerning the Ketubah, which helped shape the Jewish family). Until that time, fathers would teach their sons, and those who had no father did not study. This decree was a social regulation that derived from an existing need. Later on the schools served those whose parents were alive as well and thus became the parents' delegate (Babylonian Talmud). Following the cultural contexts and industrial and technological developments, the relationship of the parents with the teachers in particular and with the school in general underwent transitions. The current study seeks to inquire, through questionnaires administered to teachers and parents throughout Israel, whether the current structure of the parent-teacher meeting is compatible with our technological era, and to try and estimate which functions it continues to fulfill (the ethical and emotional) and which have become redundant (the cognitive).

\section{Research Variables}

\subsection{Parent Involvement}

The teacher is a delegate of the parents. They impart to him or her the duty of educating their child. This mission grants the teacher significant power, both moral and practical. The parents do not disappear from the scene once they have delegated their educational authority. On the contrary, from that moment on they form a partnership with the teacher and expect constant and well-organized communication (Religious Education Administration, n.d.). "Contact between the school and the home is a sensitive issue in Israel and in Western countries, one that for many years had no solution. This contact is replete with expectations and hopes, side by side with tensions and conflicts" (Friedman, 2010). Parent involvement in the school is manifested in a wide range of actions that concern parents' manner of organization at the school and their contact with the school staff. All these have in common the wish to reduce the discrepancies between the outlook of the home and that of the school (Friedman \& Fischer, 2002). Parent involvement in their children's education is a right that is rooted in the foundations of democracy (Friedman \& Fisher, 2002; Troen, 2004). According to the Israeli Ministry of Education (Vidislavsky et al., 2005) it is also an obligation. The parent-school relationship centers on the child's development, functioning, achievements, and mental health (Katzenelson, 2014). Many studies have indicated the association between parent involvement and the academic achievements of students of different ages (Trager, 2012; Vidislavsky \& Shemesh, 2010; Stevenson, David L., and David P. Baker. 1987; Fan, Xitao. 2001). 
In addition to parent involvement, the socioeconomic status of the home also creates opportunities and motivation that have a direct effect on the student (Litwak, Meyer, \& Mickelson, 1974, in Friedman, 2010; Trager, 2012). The weak position of parents who belong to socially marginalized groups or to a lower socioeconomic class, stems from the great challenge of bringing their complex identity and their shaky connection to the academic discourse into the school, and of creating communication with the teachers (Gur-Ziv \& Zalmanson-Levy, 2005). Israel's educational system has set itself major goals concerning the policy of educational promotion and reducing the academic and social gaps of students from a low socioeconomic status, in order to facilitate social mobility, and it has allocated many resources for this purpose (Division of Education and Welfare Services, Ministry of Education, 2016). Nonetheless, there are also many studies indicating that parent involvement has a greater effect than socioeconomic status. This is evident from the fact that even among weak strata, parent involvement encourages achievements, since in a society characterized by social mobility parents from allegedly low social classes are interested in encouraging their children to acquire an education in order to improve their social status. Another possibility is that high expectations for children's success affect academic achievements, unrelated to social background and socioeconomic status (Trager, 2012).

\subsection{The Evolvement of Parent Involvement}

Four main stages may be noted in the development of the school-home relationship. In the first stage, with the initial development of Israel's educational system, the government emphasized the principle of equal education for all, which led to a separation between the parents and the school, i.e., a closed door policy that generated a considerable social and cognitive distance between the school and the surrounding community. The home was perceived as a barrier to the uniformity of the educational system. Furthermore, educational failures were explained by citing the negative effect of the student's home environment, with the conclusion being that the school must compensate for the oversights of the home. In the second stage, towards the late 1960s, the Ministry of Education began to explore the school-home relationship in recognition of the injustice done to the home. The ministry's policy was compatible with the theory of reciprocity and joint protection, in which the parents and the school are full partners in the children's education, in an attempt to strengthen the school's relationship with the home. In the two final stages, the schools embraced the open door policy. In the latter half of the 1980s, the Ministry of Education decided to stress the topic of community-based education, characteristic of the third stage in development of the school-home relationship. Strengthening the school-community relationship was perceived as a means of improving the educational work performed at the school. At this stage, greater parent involvement in formal educational processes is evident. The open door policy persevered in the fourth stage of development as well, in the first decade of the 21 st century. Nonetheless, this stage was also characterized by increasing trends in favor of a closed door policy, both following conflicts between parents and the educational establishment and due to over-involvement by parents (Friedman, 2010).

\subsection{Types of Parent Involvement}

There are different options with regard to school-home communication. The basic level focuses on routine communication, and involves the student's regular academic and behavioral performance at school and formal encounters in the form of parent-teacher meetings. Another level can take the interrelations between the school and the student's environment one step forward outside the school walls by building programs involving varied fields of interest and courses of action. The significance of the school-community relationship is in its contribution to achieving educational goals in the school, i.e., raising the level of achievements and motivation to study and training good citizens (Noy, 1992).

\subsection{Parent-teacher Meetings}

Efficient communication with parents mainly takes the form of regular institutionalized communication. Parent-teacher meetings are one of the most important channels of communication between the school and the home (Religious Educational Administration, n.d.). According to the Israeli Ministry of Education (2014), parent-teacher meetings are planned encounters between the parents and the teacher. There are three possible types of parent-teacher encounters. The first is a general parent-teacher meeting where the teacher meets with all class parents. Another is the individual parent-teacher meeting where the teacher meets with each student's parents alone or in the presence of the student. The third type is unofficial encounters during the year, such as on open days through direct conversations, by telephone or otherwise. The purpose of the encounters is to provide knowledge and guidance (cognitive aspect), to maintain a constant dialogue (emotional aspect), and to create parental involvement in class and school happenings (ethical aspect). The relationship with the parents is an important component of creating a good atmosphere in the class and school and the encounter is one of the most important channels of communication with 
the parents. The anticipated results of the parent-teacher meeting as perceived by teachers are, from the cognitive aspect: successful conveying of the educational message and information about parent expectations; and on the emotional level: a sense of support, receiving a feeling of openness and understanding the joint endeavor. Parents receive a sense of significance, collaboration is formed with regard to developing a "uniform front" on behalf of the child. On the ethical-practical level: parents raise ideas concerning ways of getting close to the child through school, maintaining a leading group, class leadership that provides assistance during the year (Religious Educational Administration, n.d.).

Parent involvement, previously maintained in a direct form, such as through face-to-face encounters, is now entering the digital era.

\section{Computer-assisted Communication in Schools}

Computer-assisted communication is a developing research focus. Rapid technological development and computer-assisted communication in the school are a major component of this research. In the current chapter we shall examine previous research on computer-assisted communication in schools and inspect technology as a means of communication within the learning environment among the various factors involved in the student's formal education.

Technology and its development have undergone many changes over time. Where encounters between parents and teachers, and communication between school systems and school figures once took place face-to-face, today technology-based communication is gradually occupying a major role, one that does not require physical presence. Sometimes the latter replaces the former and sometimes it adds another level. The challenge of developing computer-assisted communication involves clarifying where introducing computer-assisted communication can indeed help make essential communication more accessible (Pollock, 2012).

According to Juniu (2009), use of computer assisted teaching has the potential to support school-home communication and to break down barriers of geographical distance and time, barriers encountered by teachers and parents. Computer mediated communication (CMC), such as video conferencing, telephone conferencing, online correspondence, and e-mail, are efficient means for increasing school-home communication and provide parents, teachers, and students with a way of remaining connected and updated, as well as encouraging regular communication (Perkins, Matthew \& Pfaffman, 2006, in Juniu, 2009). Parents who are connected to the internet find that it is a more convenient and less faulty technique for contact with the teacher than face-to-face communication (Merkley, Schmidt, Dirksen, \& Fulher, 2006, in Juniu, 2009).

Use of CMC tools by the school facilitates teacher-parent communication and helps prevent the need for telephone contact or attending parent-teacher meetings that disrupt the parent's workday (Beverly, 2003). Use of computer-assisted communication in the learning environment has many advantages, of which a great deal have been studied in the literature.( Cuban, Larry,1986, Handler, Marianne G. 1993, Bobbitt, L. Michelle, and Pratibha A. Dabholkar (2001), Venkatesh, Viswanath, James YL Thong, and Xin Xu. (2012|)).

Juniu (2009) found that posting grades online encourages parent involvement, increases student motivation, and consequently improves students' academic achievements.

Updating grade information and the effect on students are only one example of the many advantages of using computer-assisted communication in schools. In addition to grades, it is also necessary to discuss the student's behavior in class in order to facilitate cooperation on issues that require prompt attention and solutions. The benefit of the synchronization formed following the parent-teacher conversation is the opportunity it awards to think about the situation and to respond before acting, possibly providing a better understanding of the situation and of the appropriate response (Zhao, 2004, in Juinu, 2009).

Parent involvement is another benefit. According to Juniu (2009), increasing home-school communication through dense communication enabled by daily technologies, leads to enhanced parent involvement and encourages home support of school behavior.

\subsection{Technological Channels}

There are many ways of maintaining constant school-parent communication. Of the variety of conspicuous technological methods of communication, Juniu (2009) brings several examples. First of all, there is the online calendar, which informs parents of all events taking place at the school. There is also a system for online posting of grades, described in more detail by Davidovitch and Yavich (2015), where grades are posted as part of the MASHOV system, a technological change introduced in Israeli schools in recent years. The most common and daily methods 
are by e-mail correspondence and texting, which serve as additional channels of communication. Added benefits of these stem from the opportunity they provide for communication without a face-to-face conversation with the teacher. Teachers are constantly available and can choose when to respond. Furthermore, when e-mailing/texting the communication can be one-one-one or one-on-many, i.e., it is possible to send an e-mail/text message to a group of people rather than only to one person, and thus provide relevant information to several parents/teachers at a time. In addition, e-mail affords the possibility of adding files and pictures, which can increase communication options and enable the transfer of a wide range of information (Juniu, 2009).

The assimilation of technological channels of communication in the school depends on many factors. One major factor is the type of leadership provided by the school principal, i.e., to what degree the leader (in a school the principal) takes responsibility for enhancing and developing innovative applications at the school. Many studies have found the most appropriate type of leadership to be that of the transforming leader (Kafetsios, Konstantinos, John B. Nezlek, and Thanai Vassilakou. (2012), Kafetsios, Konstantinos, John B. Nezlek, and Aikaterini Vassiou. (2011), Lunenburg, Fred C. (2011)).

Moreover, the closer the principal is to the school staff, the more motivation they will have to assimilate changes in the school (Moolenaar, Daly \& Sleegers, 2010).

Beyond the significance of the type of leadership, another factor is the motivation of members of the school community, including: teachers, parents, managers, etc. Pollock (2012) attempted to facilitate community organization and found that people were interested in assimilating technological changes in school communication, for instance teachers wished to have easier access to student data, managers wanted to forego paperwork, teachers and students wanted more communication concerning students' academic interests. Following the increased motivation of the research participants an extensive communications project was formed in the school studied, using updated technology.

\subsection{Structure of the Parent-teacher Meeting in the Technological Era}

Parent-teacher meetings have a variety of structures, of which the main form is the parent's presence at the school for a face-to-face meeting with the teacher. Schools differ in the identity of those present at the meeting, for example some schools require the attendance and participation of students, and so on. Schools also differ in the contents of the meeting. At most schools the contents of the meeting will be previous and present academic and social functioning in class, but some schools focus on issues related to developing and enhancing the child's personality, i.e., guiding the child in achieving individual work. In these schools the parent-teacher meeting is a place of encounter for the parent, teacher, and student, aimed at empowering and guiding the child to further development of his or her skills and personality.

At present, no technological platform is used in Israeli classes instead of the parent-teacher meeting. However there is a MASHOV system for managing learning in secondary schools that provides parents with updated information about their children. According to Yavich and Davidovitch (2015), the MASHOV system at Israeli secondary schools is perceived as an essential technological means for introducing change. They also found that the growing use of computerized systems at schools, and specifically the MASHOV, increases the efficacy of pedagogic management.

\section{Parent Understanding}

Few studies have been carried out on the topic of parent-teacher meetings in the technological era, and none on the possibility of changing the current structure of parent-teacher meetings to a computer-assisted structure, in light of the many technological changes in daily life and in schools in particular.

As mentioned, parent-teacher meetings take different forms, but they have a common structure, and such meetings are at present mandatory in all schools. The question is whether in an era when daily technology is making communications more accessible and easy to use, it is necessary to change the structure of the parent-teacher meeting or perhaps even to question the need for such meetings. In an era when the media is making communications easier than ever, the infrastructure of communications in education often seems quite outdated (Pollock, 2012).

Nonetheless, use of technological communication does not provide a response to all home-school communication needs. There are various communication tools, and technological media is one of these. In order to encompass all possible school-home communication needs it is necessary to use as many forms as possible, including face-to-face communications and use of daily technology.

But use of computer-assisted media raises another dilemma. Some families cannot afford these media, and this creates inequality. The socioeconomic status of the school community must be taken into account when considering 
the integration of technology in daily school communication.

The purpose of the current study is to empirically examine the hypothesis whereby use of computer-assisted communication and parent involvement affects parent understanding. Specifically, does parent involvement mediate the effect of computer-assisted communication on parent understanding, such that use of computer-assisted communication increases parent involvement, which in turn increases parent understanding?

The effectiveness of parent involvement in parent-teacher meetings, as dependent on use of computer-assisted communication, will be explored on three dimensions:

1. Cognitive - for instance, providing information in various areas.

2. Emotional - for instance, receiving a positive experience of parent-teacher meetings.

3. Ethical - for instance, parent-teacher meetings as a tool for conveying messages.

In addition, parent involvement in parent-teacher meetings shall also be examined with regard to demographic variables: sex, age, country of birth, socioeconomic status of the student's home, number of individuals in the family, type of role (teacher/parent).

The research hypothesis is that there is an association between computer-assisted communication and parent involvement and also between parent involvement and parent understanding. Furthermore, we hypothesize that use of computer-assisted communication and parent involvement have an effect on the variable of parent understanding, and specifically, that parent involvement mediates the effect of computer-assisted communication on parent understanding, such that computer-assisted communication increases parent involvement, which in turn increases parent understanding.

\section{Method}

\subsection{Description of the Sample}

The sample consisted of 107 respondents from all regions of Israel, and was formed using a non-probabilistic sampling method of the volunteer and snowball type. Seventy eight of the respondents were women, and 29 men. Fifty eight of the respondents were parents and 49 teachers. The mean age of all respondents was 36.09 years. In addition, other demographic variables were taken into account, for example the distribution of respondents' marital status showed that $91.6 \%$ of all respondents were married. The number of children ranged from $0-9$, with the most common being 4 per family. The distribution of schooling level showed that $2 \%$ reported elementary schooling, $10 \%$ secondary schooling, 3\% diploma studies, 65\% had a Bachelor's degree, 19\% had a Master's degree, and 2\% had a $\mathrm{PhD}$.

\subsection{Research Tool}

The effectiveness of parent-teacher meetings was examined using a questionnaire that explored use of computer-assisted communication and personal involvement, as well as parent involvement and parent understanding, and finally, how parent involvement mediates use of computer-assisted communication and parent understanding. It included 22 items constructed of three dimensions: cognitive, emotional, and ethical (Hativa, 2015). Respondents were requested to rank 21 items, and to state to what degree each statement concerning the three dimensions is true for them. The ranking was performed on a Likert scale, with a range of 1 ("not at all") to 5 ("very much"). Item no. 22 was presented as an open-ended question that enabled respondents to offer suggestions for improving the efficacy of parent-teacher meetings from their unique perspective. Scale reversals were carried out.

\subsection{Procedure}

During the months of the research, an appeal was made to our target population, teachers and parents from all regions of Israel, to take part in the study. The research population was approached via different media: telephone, e-mail, and social networks, providing a short explanation of the research topic and asking them to participate. The research procedure took 4 months, and respondents were asked to devote 10 minutes to the study. Each participant signed an informed consent form before completing the questionnaire (see appendices). Participation in the study took one of two forms, according to the respondent's group of affiliation. The first form was intended for the teacher group and required respondents to complete the questionnaire attentively. At first, respondents were given a short sociodemographic questionnaire. In the next stage, respondents completed a questionnaire that included statements ranked by degree of consent. The final stage included an open-ended question in which respondents could freely state their opinion on the research topic. The second form was intended for the parent group, and participants in this group were asked to go through an identical process reflecting their unique perspective. 


\section{Results}

\subsection{Descriptive Statistics and Calculation of the Research Variables}

The dependent variable in the study was parent understanding and it was composed of three dimensions: emotional, ethical, and cognitive. The mean for parent understanding was 3.70, with a standard deviation of 0.86 ; responses were given on a scale of 1-5. The mean for the emotional dimension was 3.91, with a standard deviation of 0.99 . The mean for the ethical dimension was 3.63, with a standard deviation of 0.99 , while the mean for the cognitive dimension was 3.55 , with a standard deviation of 0.92 . The range of responses for all three dimensions was 1-5.

The independent variables in the study are use of computer-assisted communication and parent involvement. The mean score for use of computer-assisted communication was 3.35, with a standard deviation of 0.91 and responses given on a scale of 1-5. The mean score for parent involvement was 3.53 , with a standard deviation of 0.78 and responses on a scale of 1-5.

\subsection{Examination of the Research Hypotheses}

As stated, the first hypothesis regarded the association between use of computer-assisted communication and parent involvement. It was hypothesized that use of computer assisted teacher-parent communication would increase parent involvement. A Pearson correlation analysis was conducted in order to examine the hypothesis, and a strong significant positive correlation was found $(r=0.75, \mathrm{p}<0.001)$, such that the greater the use of computer-assisted communication the greater the parent involvement and the better the parent-teacher communication.

The second hypothesis regarded the effect of parent involvement on parent understanding of the school and of their children. In order to examine the hypothesis, the association between parent involvement and parent understanding was explored. A Pearson correlation held between these two variables found a strong significant positive correlation $(\mathrm{r}=0.77, \mathrm{p}<0.001)$ that confirmed the hypothesis. This correlation shows that the greater the parent involvement the greater the parent understanding, and vice versa. Furthermore, the variable of parent understanding was said to have been composed of three dimensions: emotional, ethical, and cognitive. Accordingly, correlations were examined between emotional involvement and the three dimensions composing the variable of parent understanding. The values of the correlations are presented in Table 1. Confirming the hypothesis, a medium significant positive correlation was found, such that the greater the personal involvement the greater the parent's emotional understanding of the child $(\mathrm{r}=0.68, \mathrm{p}<0.001)$. At the same time, a high significant positive correlation was found between personal involvement and the ethical dimension, such that the greater the personal involvement the greater the ethical dimension $(\mathrm{r}=0.72, \mathrm{p}<0.001)$. Finally, a strong significant positive correlation was also found between parent involvement and the parent's cognitive understanding of the child, such that the greater the personal involvement the greater the parent's cognitive understanding of the child $(r=0.73, p<0.001)$. Finally, correlations were held between the three dimensions to examine the high correlation between them, leading to the conclusion that they all belong to the same variable. The high correlations found are also presented in Table 1 and they confirm that the three dimensions refer to the same factor.

Table 1.

\begin{tabular}{ccccc}
\hline & Parent involvement & Emotional & Ethical & Cognitive \\
\hline Parent involvement & 1 & $0.68 * *$ & $0.72 * *$ & $0.73 * *$ \\
Emotional & - & 1 & $0.75 * *$ & $0.80 * *$ \\
Ethical & - & - & 1 & $0.81 * *$ \\
Cognitive & - & - & - & 1 \\
\hline
\end{tabular}

$$
* * \mathrm{p}<0.001 ; \mathrm{N}=107 \text {. }
$$

The third research hypothesis relates to parent involvement as a mediating variable between use of computer-assisted communication and parent understanding of the child, such that a rise in use of computer-assisted communication leads to increased parent involvement, and eventually to increased parent understanding. In order to examine this hypothesis, a block regression was conducted, such that the independent variable of computer-assisted communication was entered in the first block, with the dependent variable being parent understanding. In the second block the variables of computer-assisted communication and parent involvement were entered as independent variables and the variable of parent understanding was entered as the dependent variable. If parent involvement is a mediating variable, we would expect the effect of computer-assisted communication to diminish from the first to the second block. In all blocks, the dependent variable of parent understanding refers to the overall measure that includes 
all three dimensions (emotional, ethical, and cognitive). In addition, in the regression analysis the demographic variables were entered as well in order to examine their effect on the variable of parent understanding, and they were entered in the third block.

To begin with, the three blocks in the regression model were found to be significant. With regard to the mediation hypothesis, the effect of computer-assisted communication on parent understanding was found to diminish between the first and the second block, which included the variable of parent involvement. In the first block $[F(1,98)=149.26$, $\mathrm{p}<0.001]$ computer-assisted communication was found to affect parent understanding, such that the greater the computer-assisted communication the greater the parent understanding $(b=0.74, t=12.22, \mathrm{p}<0.001)$, while in the second block $[\mathrm{F}(2,97)=103.93, \mathrm{p}<0.001]$ computer-assisted communication was indeed found to have a significant effect on parent understanding $(b=0.41, t=4.79, \mathrm{p}<0.001)$, but this effect was lower when parent involvement was also entered in the regression model. These findings support the hypothesis that parent involvement is a mediating variable between computer-assisted communication and parent understanding, such that computer-assisted communication leads to increased parent involvement, which in turn leads to increased parent understanding of their children.

Secondly, the third block examined the effect of the demographic variables together with computer-assisted communication and parent involvement - on parent understanding. The regression model was found to be significant $[\mathrm{F}(8,91)=27.39, \mathrm{p}<0.001]$. The regression findings indicated that computer-assisted communication and parent involvement predict $68.1 \%$ of the variance in the variable of parent understanding of the child (adjusted R2 $=0.68$ ). Specifically, the variable with the greatest effect on parent understanding was parent involvement $(B=0.45)$, such that greater parent involvement leads to greater parent understanding $(b=0.50, t=4.84, p<0.001)$. In addition, an effect was also found for teacher-parent computer-assisted communication, such that greater use of technological means leads to greater parent understanding $(b=0.38, t=4.21, p<0.001)$. None of the demographic variables was found to have a significant effect on parent understanding.

\section{Discussion}

The major research question of the current study is whether there is need for change in the structure of parent-teacher meetings, in light of the various technological changes in recent years. Namely, have the technological changes themselves generated a change in the parent-teacher relationship and/or transformed it into one that is managed differently than previously.

In order to examine this question, three different dimensions of parent understanding of the child's state were integrated to form one research variable of teacher/parent understanding. This variable was utilized to explore the relationship between parent involvement and computer-assisted communication - and parent understanding, and thus reach a conclusion about the need for change in parent-teacher meetings in the technological era.

Parent understanding was composed of three major dimensions manifested in education: the cognitive dimension, the ethical dimension, and the emotional dimension. In order to verify that these three dimensions are indeed interrelated with regard to parent understanding, a Pearson correlation was conducted between the three dimensions, and they were indeed found to be interrelated. It is not known which affects the other, therefore we recommend further research to explore the relationship between the dimensions within the variable of parent understanding.

Examples of the different dimensions within parent understanding can also be seen in the questionnaire administered in order to investigate the research question.

For example, in order to investigate the cognitive dimension of parent involvement, a sample item was "You have realistic expectations of the school and of the student", where the respondent replied in a range of 1 (not at all) to 5 (very much). In addition, in order to investigate the ethical dimension, a sample item was "During the parent-teacher meeting we conducted an extensive conversation about the student's file", and on the emotional dimension, a sample item was "I had a positive experience during the parent-teacher meeting". Thus, the dimensions were intended to investigate the teacher/parent's outlook and thus comprised the variable of parent understanding.

In addition to the quantitative section mentioned above, the questionnaire had a qualitative section that will be expand on in this discussion. In this section, respondents were asked to offer suggestions for enhancing the efficacy of the parent-teacher meeting in its current structure. In order to best analyze responses to this section, these were divided into categories, with each category representing a type of reply. Examples of the categories are presented below. 


\begin{tabular}{|c|c|c|c|c|c|}
\hline Content & Convenience & Time & Technique & Frequency & Attendance \\
\hline $\begin{array}{l}\text { The } \\
\text { teacher-parent } \\
\text { dialogue will } \\
\text { lead to a decision } \\
\text { concerning } \\
\text { expectations on } \\
\text { different topics } \\
\text { and application } \\
\text { will be } \\
\text { examined. }\end{array}$ & $\begin{array}{l}\text { Distribution into } \\
\text { several days. At } \\
\text { the beginning of } \\
\text { the year an } \\
\text { announcement } \\
\text { will be made that } \\
\text { parent-teacher } \\
\text { meetings will be } \\
\text { held throughout } \\
\text { the year. }\end{array}$ & $\begin{array}{l}\text { Splitting the } \\
\text { parent-teacher } \\
\text { meeting into } \\
\text { two days and } \\
\text { giving more } \\
\text { time to meet } \\
\text { with each } \\
\text { parent. }\end{array}$ & $\begin{array}{l}\text { Sheet with } \\
\text { practical } \\
\text { decisions, how } \\
\text { to continue } \\
\text { and who is } \\
\text { responsible } \\
\text { for each issue } \\
\text { (parent/ } \\
\text { teacher/ } \\
\text { principal/ } \\
\text { student) }\end{array}$ & $\begin{array}{l}\text { More individual } \\
\text { parent-teacher } \\
\text { meetings once a } \\
\text { month, and the } \\
\text { option of } \\
\text { speaking with } \\
\text { the teacher in the } \\
\text { evenings }\end{array}$ & $\begin{array}{l}\text { Sharing } \\
\text { expectations of } \\
\text { the student and } \\
\text { achievements } \\
\text { with the student. } \\
\text { Taking this } \\
\text { opportunity to } \\
\text { enhance the } \\
\text { student's } \\
\text { involvement and } \\
\text { responsibility }\end{array}$ \\
\hline $\begin{array}{l}\text { I would add the } \\
\text { possibility of } \\
\text { explaining to the } \\
\text { parents their role } \\
\text { as parents }\end{array}$ & $\begin{array}{l}\text { More contact with } \\
\text { the parents } \\
\text { through the school } \\
\text { website }\end{array}$ & $\begin{array}{l}\text { I would be glad } \\
\text { if more time } \\
\text { would be } \\
\text { devoted to each } \\
\text { parent. }\end{array}$ & $\begin{array}{l}\text { Preparation } \\
\text { sheet for the } \\
\text { parents before } \\
\text { the meeting. } \\
\text { What do they } \\
\text { know about } \\
\text { the child's } \\
\text { studies. }\end{array}$ & $\begin{array}{l}\text { Initiating } \\
\text { individual } \\
\text { meetings with } \\
\text { the parents } \\
\text { beyond the } \\
\text { parent-teacher } \\
\text { meetings }\end{array}$ & $\begin{array}{l}\text { At our school the } \\
\text { meetings are } \\
\text { attended by the } \\
\text { students. I think } \\
\text { that there is also } \\
\text { room for } \\
\text { teacher-parent } \\
\text { conversations } \\
\text { without the child. }\end{array}$ \\
\hline
\end{tabular}

It is evident from the responses that the great majority of respondents see room for change, i.e., the current structure of the teacher-parent meeting is not optimal. Hence, change can and should be effected.

Moreover, many respondents stated that the content of the meetings should be examined, and that there should be more of a focus on the student's future rather than on the past/present. Following extensive thought and observation of many replies concerning the content of parent-teacher meetings, we wish to offer a proposal for a possible change in the structure of the meetings. The change shall take the form of a meeting managed by a coach, who will guide the parents with the full cooperation of the teachers towards a future plan that will help the child progress and towards setting goals as well as courses of action that parents can embrace, such that the entire coaching process will help the student, the parent, and even the teacher, make the most of the parent-teacher meeting in order to help the student advance and optimally involve all factors who have a potential contribution. At this stage of the research the model is initial, as is the study itself which is a pioneer study. No study has been conducted to date on the efficacy of parent-teacher meetings and, in particular, on the structure of parent-teacher meetings in the technological era.

The current study uncovered three main findings. The first is the correlation between computer-assisted teacher-parent communication and parent involvement, such that computer-assisted communication increases parent involvement in events in the class and at school. Furthermore, there is a correlation between the parent's involvement and parent understanding of the child's condition. Finally, parent involvement was not only found to be correlated with parent understanding and computer-assisted communication, rather it also mediates the effect of computer-assisted communication on parent understanding, i.e., increases parent involvement, which in turn increases parent understanding.

Additional suggestions for further research of our pioneer research subject will be proposed below.

We found that the subject of parent-teacher meetings is one in which discussion of possible change raises many queries concerning the form this change will take and the areas in which it will be effected. We also found that, in the technological era, much use is indeed made of technology to connect between teachers and parents, and that technology enables more parent involvement in school events and more parent understanding of student functioning in class.

Since this study is a pioneer study, we propose various issues for further research - In the current study the 
respondents (teachers and parents) completed an identical questionnaire. In further studies, it would be interesting to explore the construction of a unique questionnaire for each subgroup in order to better understand the studied phenomenon. In addition, the school principal has an indirect, or sometimes direct part in the educational work, and takes part in the constant dialogue on which we have expanded. Principals were not included in the current study and, in order to receive a wider and more accurate picture, a future study that would include principals among the respondents might produce different results. Moreover, we suggest that future research explore interrelations between the different dimensions that comprise the variable of parent understanding, such as the effect of the cognitive on the emotional dimension.

\section{Acknowledgements}

The authors wish to thank Hana Silvers and Tamar Averbuch, undergraduate students of social sciences at Ariel University, for their assistance in data collection for this study.

\section{References}

Babylonian Talmud, Bava Batra, 21a.

Bobbitt, L. Michelle, \& Pratibha A. Dabholkar. (2001). Integrating attitudinal theories to understand and predict use of technology-based self-service: the internet as an illustration. International Journal of Service Industry Management 12(5), 423-450. https://doi.org/10.1108/EUM0000000006092

Cuban, Larry. (1986). Teachers and machines: The classroom use of technology since 1920. Teachers College Press.

Davidovitch, N., \& Yavich, R. (2015). Technology-related involvement: The effect of the MASHOV system on parent involvement in Israeli junior highs. Journal of International Education Research, 11(4), 243. https://doi.org/10.19030/jier.v11i4.9458

Fan, Xitao. (2001). Parental involvement and students' academic achievement: A growth modeling analysis. The Journal of Experimental Education, 70(1), 27-61. https://doi.org/10.1080/00220970109599497

Friedman, I. \& Fisher, I. (2002). Identification and alertness: Basics in parent involvement in schoolwork. Iyunim Beminhal Uve'irgun Hahinuch, 26, 8-34. [in Hebrew]

Friedman, I. (2010). School-parent relationship in Israel. Background material for Yozma work. Retrieved 18 November 2015 from http://education.academy.ac.il/. [in Hebrew]

Gur-Ziv, H. \& Zalmanson-Levy, G. (2005). School-parent relationship from a critical perspective. Hahinuch Usvivo, 27, 131-142. [In Hebrew]

Handler, Marianne G. (1993). Preparing new teachers to use computer technology: Perceptions and suggestions for teacher educators. Computers \& Education 20(2), 147-156. https://doi.org/10.1016/0360-1315(93)90082-T

Hativa, N. (2015). What does the research say about good teaching and the outstanding teacher. Hora'ah Ba'akademya, 5, 42-61. $\quad$ Retrieved 5016 April 2016 from http://sfile.f-static.com/image/users/176149/ftp/my_files/Articles/articals\%202/07062015/Ma_OmerH.pdf?id=2 2976382 [in Hebrew]

Jerusalem Talmud, Ketubot 50b.

Juniu, S. (2009). Computer mediated parent-teacher communication/La comunicación entre padre-maestro mediada por computadora. Revista Actualidades Investigativas en Educación, 9(3).

Kafetsios, Konstantinos, John B. Nezlek, \& Aikaterini Vassiou. (2011). A multilevel analysis of relationships between leaders' and subordinates' emotional intelligence and emotional outcomes. Journal of applied social psychology, 41(5), 1121-1144. https://doi.org/10.1111/j.1559-1816.2011.00750.x

Kafetsios, Konstantinos, John B. Nezlek, \& Thanai Vassilakou. (2012). Relationships Between Leaders' and Subordinates' Emotion Regulation and Satisfaction and Affect at Work. The Journal of social psychology 152(4), 436-457. https://doi.org/10.1080/00224545.2011.632788

Katzenelson, E. (2014). Relationship between parents and their children's system of education. Psychoactualya, 40-45. [in Hebrew]

Litwak, E., Meyer, H. J., \& Mickelson, C. E. (1974). School, family and neighborhood: The theory of school-community relations. New-York: Colombia University Press.

Merkley, D., Schmidt, D., Dirksen, C., \& Fuhler, C. (2006). Enhancing parent teacher communication using 
technology: A reading improvement clinic example. Contemporary Issues in Technology and Teacher Education, 6(1), 11-42. Retrieved April 8, 2007 from http://www.citejournal.org/articles/v6illanguagearts1.pdf

Ministry of Education (2014). Tips for teachers towards the first parent-teacher meeting. Organization and Administration, Ministry of Education. Retrieved 16 November 2015 from http://edu.gov.il/owlHeb/CHativa/RegulationsAndAdministrations/OrganizationandDirector/Pages/TipsforTeach ers.aspx [in Hebrew]

Moolenaar, N.M., Daly, A.J., \& Sleegers, P.J. (2010). Occupying the principal position: Examining relationships between transformational leadership, social network position, and schools' innovative climate. Educational Administration Quarterly, 46(5), 623-670. https://doi.org/10.1177/0013161X10378689

Noy, B. (1992). Fundamental principles in the process of parent inclusion in the school. Iyunim Behinuch, 57-58, 209-218. [in Hebrew]

Pedagogic Administration, Division of Education and Welfare Services, Ministry of Education. Retrieved 2 February 2016 from www.education.gov.il/michrazim/documents/2899.doc [in Hebrew]

Perkins, M., \& Pfaffman, J. (2006). Using a course management system to improve classroom communication. The Science Teacher, 73(7), 33-37.

Pollock, M. (2013). It takes a network to raise a child: Improving the communication infrastructure of public education to enable community cooperation in young people's success. Teachers College Record, 115(7).

Religious Education Administration (n.d.), Contact with parents. Ministry of Education. Retrieved 30 December 2015 from cms.education.gov.il/NR/rdonlyres/1DC1858A-0968.../chapter8.doc [in Hebrew]

Stevenson, David L., \& David P. Baker. (1987). The family-school relation and the child's school performance. Child development, 1348-1357. https://doi.org/10.2307/1130626

Trager, H. (2012). There is no education without the parents, their involvement enhances achievements. Iyunim, 13, 8-12. [in Hebrew]

Troen, Y. Regularizing the status of parents in the educational system, a comparative review. Retrieved 10 December 2015 from www.kavnet.co.il/_Uploads/dbsAttachedFiles/vaadhorim.doc [in Hebrew]

Venkatesh, Viswanath, James YL Thong, \& Xin Xu. (2012). Consumer acceptance and use of information technology: extending the unified theory of acceptance and use of technology. MIS quarterly, 36(1), 157-178.

Vidislavsky, M. \& Shemesh, D. (2010). Guide to management of parent and school work. Ministry of Education Division of Publications. [in Hebrew]

Vidislavsky, M. et al. (2005). Parent involvement in education. 4 Mems, 9. Ministry of Education, Jerusalem. [in Hebrew]

Zhao, Y., Alvarez-Torres, M.J., \& Smith, B. (2004). The non-neutrality of technology: A theoretical analysis and empirical study of computer mediated communication technologies. Journal of Educational Computing Research, 30(1-2), 23-55. https://doi.org/10.2190/5N93-BJQR-3H4Q-7704 